\title{
Biochemical and Micro-morphoanatomical Investigations on Leucojum aestivum $\mathrm{L}$.
}

\author{
Hussein Dheyaa Hussein AL-FARIS ${ }^{1}$, Ibrahim BULDUK ${ }^{2}$, \\ Ahmet KAHRAMAN ${ }^{3 *}$
}

\author{
${ }^{1}$ Usak University, Institute of Natural and Applied Sciences, Department of Molecular Biology and Genetics, 64200 Usak, \\ Turkey; husseinhdha@gmail.com \\ ${ }^{2}$ Usak University, School of Health, 64200 Usak,Turkey; ibrahim.bulduk@usak.edu.tr \\ ${ }^{3}$ Usak University, Faculty of Arts and Sciences, Department of Biology, 64200 Usak, \\ Turkey; ahmet.kahraman@usak.edu.tr (* corresponding author)
}

\begin{abstract}
Leucojum aestivum (snowflake) contains galantamine, a medication used for the treatment of Alzheimer's disease. However, polyphenolic compounds of this species were not studied earlier. Proper understanding of the polyphenolics in the species and their antioxidant properties may lead to a review of their medical use. Therefore, in this study, the polyphenolic content of $L$. aestivum was determined by UV spectrophotometric and HPLC methods. DPPH, ABTS+, and RPC assays were performed for assessment of its antioxidant potential. Flower and leaf extracts of $L$. aestivum were found to have more antioxidant activity than its bulbs. This result demonstrated that it was an important source of antioxidant compounds. Qualitative and quantitative findings showed that it contained significant amounts of polyphenols. Naringenin, rosmarinic, pcoumaric, syringic, and gallic acid compounds were identified in the leaf and flower extracts. Methanol extracts of the fowers, leaves and bulbs had no activity against pathogenic bacterial strains. The methanolic flower and leaf extracts showed the most antifungal effective against Alternaria citri. Moreover, they were found to be a slightly antifungal effective against Penicillium glabrum and Cladosporium cladosporioides. Anatomical studies were performed on leaf transverse and surface sections of $L$. aestivum and its bulb cross-section. The isobilateral leaf had tetracytic type of stomata. The mesophyll comprised arge lysigenous cavities and contained crystalline inclusions (raphide crystals). Large amounts of compound starch grains were recognized to occur in parenchyma cells in the bulb. SEM observations revealed that leaf epidermal cells had conspicuous boundaries and their membranes on periclinal walls were striate.
\end{abstract}

Keywords: anatomy; antimicrobial activity; antioxidant activity; Leucojum aestivum; micromorphology; polyphenols

\section{Introduction}

Leucojum aestivum L. is commonly used in the production of galantamine, an acetylcholinesterase inhibitor for treatment of Alzheimer's disease. L. aestivum, a species of perennial bulbous, petaloid monocotyledons assigned to Amaryllidaceae, is found in Europe and in most of the Mediterranean region. There are two species of Leucojum worldwide, $L$. aestivum and $L$. vernum, and also $L$. aestivum is naturally found in Thrace, North Anatolian Region and Beyşehir in Turkey. L. aestivum is also widely cultivated in the temperate zone in the world. The species is widespread between $1100 \mathrm{~m}$ and sea level in damp and wetland areas, such as swamps and wetlands. It grows with bulbs or seeds and usually blooms from March to June. The number of flowers per plant usually ranges from 1 to 5.2 (Atay, 1996; Cherkasov and Tolkachev, 2002; De Groot et al., 2002; Diop et al., 2007; Demir, 2014)

In the studies conducted so far, chemical properties of alkaloids found in $L$. aestivum have been focused. Investigations on sustainable production and medical resource value of medicinal plants remain limited. These limitations make it difficult to accurately evaluate the production processes of this plant. At the same time, the pharmaceutical industry has begun to receive more attention in this field. Therefore, it is important to establish rules governing the sustainable use of medicinal plants. The pharmaceutical industry is particularly interested in galantamine because it creates an economic input and increases the demand for L. aestivum. In this context, the high demand for treatment of Alzheimer's disease rendered 
L. aestivum commercially valuable and revealed the medicinal value of this plant (Simpson et al., 1996; Cherkasov and Tolkachev, 2002)

$L$. aestivum is of great importance as it contains galantamine used in the diagnosis and treatment of Alzheimer's disease. Galantamine is an alkaloid obtained from a large number of plants belonging to the Amarylidaceae family and has anticholinesterase activity. In Alzheimer's disease, it has been shown to increase the concentration of acetylcholine in the regions lacking cholinergic neurons in the brain, and therefore, galanthamine is being used in the treatment of the disease. Galantamine is a painkiller as strong as morphine. It is used as a reversal agent in anesthetic applications due to its ability to neutralize neuromuscular blockade caused by tubacuraria in Eastern Europe. Moreover, galantamine has the ability to stimulate the central nervous system. Due to this feature, it is used to reduce eye pressure in eye drops. Today, it is the raw material of many drugs in pharmacy. The bulbs of $L$. aestivum, known as "Göl Soğanı" in our country, are used for galantamine isolation (Klosi et al., 2016).

Potential use of $L$. aestivum is not just restricted to alkaloids as the Amaryllidaceae synthesizes a wide variety of polyphenols having well-known pharmacological attributes (e.g., antioxidant, antimicrobial, anticancer and anti-aging). Recent studies have demonstrated the effectiveness of natural polyphenols (e.g., antioxidant, acetylcholinesterase and butyrylcholinesterase inhibition) in Alzheimer's disease by various mechanisms (Benedec et al., 2014, 2015, 2016; Vlase et al., 2014)

Although L. aestivum is known for its galantamine content used in the treatment of Alzheimer's disease, polyphenolic compounds of this species and other Amaryllidaceae species have been studied much less. Therefore, the results of this study may provide a new approach to the properties and therapeutic uses of $L$. aestivum, which may be considered as sources of development of new medicinal products with antioxidant activity. Proper understanding of the polyphenolics and their antioxidant properties in these extracts may also allow a review of their medical use. This study also presents detailed information on anatomical and micromorphological characteristics of $L$. aestivum.

\section{Materials and Methods}

\section{Plantmaterial}

Plant material (Fig. 1) used in this study was collected in May 2018 from the Sakarya Region in Turkey. Collection and identification of this plant were made by the third author. Plant samples were stored in Herbarium Material Warehouse at Usak University. The leaves, flowers and bulbs of this plant were dried in a dark room for fifteen days, and then they were ground to 80 mesh of grain size for analysis.

\section{Chemicals}

The chemicals and solvents used in this study are of analytical purity and the chemicals used in HPLC analyzes are of HPLC purity. The solutions were filtered using 0.45 $u$ m filter (ISOLAB GmbH, Wertheim, Germany) before use. Folin-Ciocalteu reagent, sodium carbonate, aluminum chloride, DMSO, DPPH, ABTS, potassium ferri cyanide, potassium phosphate, sodium nitrite, sodium hydroxide, hydrochloric acid, trichloroacetic acid, iron chloride, gallic acid, protocolatechic acid, vanillic acid, caffeic acid, syringic acid, rosmarinic acid, para-coumaric acid, ferulic acid, sinapinic acid, genticic acid, catechin, quercetin and naringenin were purchased from Sigma Chemical Co.

\section{Ultrasound assisted extraction}

Ultrasound assisted extraction was performed in a Wise Clean WUC-D06H ultrasonic bath at $50 \mathrm{kHz}$ frequency. 1 gram of each of the dried samples was weighed in $50 \mathrm{ml}$ conical flasks and $30 \mathrm{ml}$ of solution (aqueous solution of $70 \%$ methanol) was added. It was extracted for 30 minutes. After extraction, each mixture was filtered through filter paper (WHATMAN INC. Florham Park, NJ USA) and the extract was stored in the refrigerator until analysis. Total phenolic, total flavonoid, phenolic acid content and antioxidant capacity were determined by using this extract.

\section{Determination of total phenolic content}

The total phenolic content of the samples was determined by the Folin-Ciocalteu method developed by Elzaawely and Tawata (2012). $500 \mu \mathrm{l}$ of extract, $250 \mu \mathrm{l}$ of Folin-Ciocalteu reagent and $7250 \mu \mathrm{l}$ of deionized water were transferred to $10 \mathrm{~mL}$ tubes, mixed and left for 5 minutes in a dark environment. Then, $2000 \mu \mathrm{l}$ of sodium carbonate $\left(7.5 \% \mathrm{Na}_{2} \mathrm{CO}_{3}\right)$ was added to the mixture and the total mixture volume was $10 \mathrm{~mL}$ and then the mixture was left in the dark environment for 30 minutes and then its absorbance was measured with a UV spectrophotometer (Shımadzu UV-1800 spectrophotometer) at a wavelength of $765 \mathrm{~nm}$. Gallic acid was used as standard in this experiment and the results were expressed as mg gallic acid equivalent per $1 \mathrm{~g}$ dry weight (mg GAE / $1 \mathrm{~g} \mathrm{~KB}$ ).

\section{Determination of total flavonoid content}

The total flavonoid content of the samples was determined by aluminum chloride colorimetric method (Chang et al., 2002). $50 \mu \mathrm{l}$ of extract, $950 \mu \mathrm{l}$ of methanol and $6400 \mu \mathrm{l}$ of deionized water were transferred to $10 \mathrm{ml}$ tubes, then $300 \mu \mathrm{l}$ of sodium nitrite $\left(5 \% \mathrm{NaNO}_{2}\right)$ solution was added.

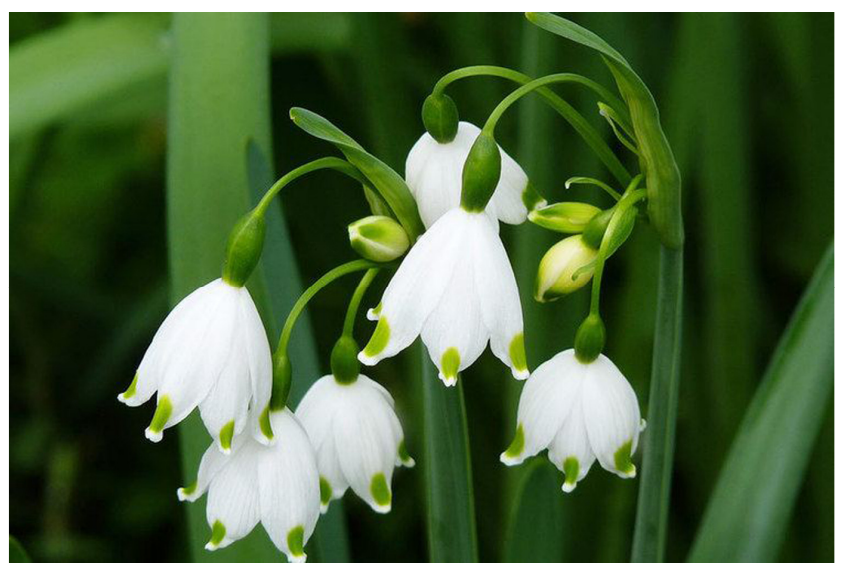

Fig. 1. L. aestivum L. (https://www.wikiwand.com/en/Leucojum) 
1384

Then $300 \mu \mathrm{l}$ of aluminum chloride $\left(10 \% \mathrm{AlCl}_{3}\right)$ solution was added to the mixture and it was left for 5 minutes, then $2000 \mu \mathrm{l}$ sodium hydroxide $(4 \% \mathrm{NaOH})$ solution was added to the mixture. The mixture was allowed to stand in the dark for 15 minutes and its absorbance was measured at $510 \mathrm{~nm}$ using a UV spectrophotometer (Shımadzu UV-1800 spectrophotometer). Catechin was used as standard in this analysis, and the total flavonoid content was expressed as $\mathrm{mg}$ catechin equivalent per $\mathrm{mg}$ of dry weight (mgCAE / 1 g. DW.).

\section{Antioxidant activity analysis}

2,2-Dipenyl-1-Picril-Hydrazile test (DPPH): The antioxidant activity of the extracts was determined by the 2,2-diphenyl-1-picril-hydrazile (DPPH) test as described in the previous methods (Villano et al., 2007). $300 \mu \mathrm{l}$ of each extract was mixed with $5.7 \mathrm{~mL}$ of DPPH solution and allowed to stand at room temperature in the dark environment for 1 hour, and its absorbance was measured by UV spectrophotometer (Shimadzu UV-1800 spectrophotometer) at $515 \mathrm{~nm}$. Ascorbic acid was used as standard in this analysis. The scavenging effect of the DPPH radical for each sample was determined by the following formula:

\% Inhibition $=\left[\left(A_{\text {blank }}-A_{\text {sample }}\right) / A_{\text {blank }}\right] \times 100$

Ablank: Absorbance of control solution (AA)

A sample: Absorbance of the mixture

$A B T S^{+}$radical cation test: Antioxidant activities of the sample were determined by inhibition of $\mathrm{ABTS}^{+}$radical cation test (Thaipong et al., 2006). This method is based on the inhibition of $\mathrm{ABTS}^{+}$radical cation produced by the oxidation of 2,2'-azino-bis (3-ethylbenzothiazoline-6sulfonic acid) and potassium persulfate $\left(\mathrm{K}_{2} \mathrm{~S}_{2} \mathrm{O}_{8}\right) .2 .6 \mathrm{mM}$ potassium persulfate and $7.4 \mathrm{mM} \mathrm{ABTS}{ }^{+}$were used as the stock solution. The working solution was prepared by mixing two stock solutions in equal amounts (1:1) and left in the dark at room temperature for 12 hours. Then, $1 \mathrm{~mL}$ of $\mathrm{ABTS}^{+}$solution was diluted with $60 \mathrm{~mL}$ of methanol to obtain $1.1 \pm 0.02$ unit absorption at $734 \mathrm{~nm}$ wavelength in the UV spectrophotometer. $150 \mu \mathrm{l}$ of extract and $2850 \mu \mathrm{l}$ of $\mathrm{ABTS}^{+}$solution were mixed and allowed to react in a dark room for 2 hours. The absorbance was then measured at a wavelength of $734 \mathrm{~nm}$. The standard solution used in this test is Gallic acid. The antioxidant activity of each sample was expressed as \% inhibition of $\mathrm{ABTS}^{+}$radical cation. The percentage inhibition of $\mathrm{ABTS}^{+}$radical was calculated by the following formula.

$\%$ Inhibition $=\left[\mathrm{A}_{0}-\left(\mathrm{A}_{\mathrm{t}} \mathrm{-B}\right)\right] / \mathrm{A}_{0} \times 100$

$\mathrm{A}_{0}$ : Absorbance of the control solution over time.

$\mathrm{A}_{\mathrm{t}}$ : Absorbance of antioxidant over time $=6 \mathrm{~min}$;

B: Absorbance of the sample.

Determination of reduction capacity: The reduction capacity of plant extracts was determined by Oyaizu (Oyaizu, 1986). The reducing agent reduces iron ions $\left(\mathrm{Fe}^{3+}\right)$ to iron ions $\left(\mathrm{Fe}^{2+}\right)$ and the absorbance of the Prussian blue color formed by the addition of $\mathrm{FeCl}_{3}$ is measured. Various concentrations of plant extracts were mixed with $2500 \mu \mathrm{l}$ phosphate buffer $(0.2 \mathrm{M}, \mathrm{pH}$ 6.6) and $2500 \mu \mathrm{l} 1 \%$ potassium ferricyanide $\left(\mathrm{K}_{3} \mathrm{Fe}(\mathrm{CN})_{6}\right)$ and then incubated at $50{ }^{\circ} \mathrm{C}$ for 20 minutes. After cooling the mixture, $2500 \mu \mathrm{l}$ of $10 \%$ trichloroacetic acid (TCA) was added and centrifuged at $2500 \mathrm{rpm}$ for 10 minutes. The topsheet was mixed with solution $(2500 \mu \mathrm{l})$, distilled water $(2500 \mu \mathrm{l})$ and a freshly prepared $0.1 \%$ ferric chloride solution $(500 \mu \mathrm{l})$ and its absorbance was measured at $700 \mathrm{~nm}$. Ascorbic acid was used as standard solution. The increased absorbance of the reaction mixture indicates an increase in the reducing power (Jayanthi and Lalitha, 2011).

\section{Determination of total anthocyanin}

The total anthocyanin content of the extracts was determined spectrophotometrically using different $\mathrm{pH}$. For the measurements of the extracts prepared, buffer solutions of $\mathrm{pH}_{1.0}$ (hydrochloric acid-potassium chloride) and $\mathrm{pH}_{4.5}$ (acetic acid-sodium acetate) were prepared. $500 \mu \mathrm{l}$ and 9500 $\mu l$ of each extract were mixed with $\mathrm{pH}_{1.0}$ buffer solution and $500 \mu \mathrm{l}$ of each extract was mixed with $9500 \mu \mathrm{l} \mathrm{pH} \mathrm{pH}_{4.5}$ buffer solution and after 2 hours, they were measured separately at 510 and $700 \mathrm{~nm}$ wavelengths for each (Giusti et al., 1999). The total anthocyanin content was calculated using the following formula using cyanidine-3-glycoside equivalent:

$$
\mathrm{A}=\left[\left(\mathrm{A}_{510}-\mathrm{A}_{700}\right) \mathrm{pH}_{1.0}-\left(\mathrm{A}_{510}-\mathrm{A}_{700}\right) \mathrm{pH}_{4.5}\right]
$$

The results were expressed as the cyanidine-3-glycoside content $(\mu \mathrm{g} \mathrm{cg}-3$-glkt / $\mathrm{g} \mathrm{KB})$ of the sample.

\section{Determination of polyphenolic compounds by HPLC}

Agilent 1260 series HPLC device equipped with C18 column $(4.6 \mathrm{~mm} \times 150 \mathrm{~mm}, 5 \mu \mathrm{m})$ was used for the determination of polyphenolic compounds. Mobile phase A was water containing $0.02 \%$ trifluoroacetic acid (TFA), while mobile phase $\mathrm{B}$ was methanol containing $0.02 \%$ trifluoroacetic acid (TFA). The flow rate of the mobile phase was kept constant at $0.5 \mathrm{~mL} / \mathrm{min}$. The gradient conditions were as follows: $0-5 \mathrm{~min}, 25 \% \mathrm{~B} ; 5-10 \mathrm{~min}, 25$ $30 \% \mathrm{~B} ; 10-16 \mathrm{~min}, 30-45 \% \mathrm{~B} ; 16-18 \mathrm{~min}, 45 \% \mathrm{~B} ; 18-25$ min, $45-80 \%$ B; $25-30$ min, $80 \%$ B; 30-40 min, $80-25 \%$ B. The temperature of the column was kept constant at $25^{\circ} \mathrm{C}$. The injection volume was $10 \mu \mathrm{l}$. Detection wavelengths of DAD were adjusted in four selected positions $(254,275$, 305 and $320 \mathrm{~nm}$ ) (Wen et al., 2005). The analysis method is presented in Table 10.

\section{Antimicrobial activity and antifungal effects (in vitro)}

Plant extraction: 25 grams of dried and ground plant samples were weighed and transferred to dark flasks, $40 \mathrm{~mL}$ of ethanol and $10 \mathrm{~mL}$ of deionized water were added and mixed, respectively, and stored in the dark at room temperature. After 48 hours, the mixture was filtered with filter paper (WHATMAN INC. Florham Park, NJ USA) and the residue was re-extracted with an equal volume of solvent. After 48 hours, the procedure was repeated. The combined supernatants were dried by distillation apparatus and dissolved in $300 \mu \mathrm{l}$ of DMSO, weighing $0.250 \mathrm{~g}$ of each on a sensitive balance. The obtained samples were used in antifungal and antibacterial activity assays.

Antimicrobial analysis: Five bacteria were used in antibacterial analysis (Gram positive: Bacillus subtilis and Staphylococcus aureus / Gram negative: Pseudomonas aeruginosa, Escherichia coli and Klebsiella pneumoniae). Petri dishes containing Mueller Hilton Agar $(25 \mathrm{ml})$ were cultured ( $0.5 \mathrm{Mc}$ Farland) and inoculated $20 \mu \mathrm{l}$ of a sample into each well by opening $6 \mathrm{~mm}$ wells in the middle. The 
results $(\mathrm{mm})$ were then evaluated after incubation in an oven at $37^{\circ} \mathrm{C}$ for $18-24$ hours (Ghaedi et al., 2015).

Antifungal Analysis: Eight fungi (Mucor plumbeus, Trichoderma longibrachiatum, Fusarium solani, Penicillium glabrum, Alternaria citri, Cladosporium cladosporioides, Trichoderma atroviride, Penicillium janthinellum) were used in antifungal analysis. $6 \mathrm{~mm}$ wells were drilled into the centers of the petri dishes containing Sabouraud dextrose $\operatorname{agar}(25 \mathrm{ml})$ and $20 \mu \mathrm{l}$ of each sample was inoculated from each sample and the molds were cultured. It was then allowed to incubate in the dark at room temperature for one week. Results were evaluated after incubation (Berber, 2013).

\section{Anatomicalmethod}

Anatomical investigations were performed using fresh specimens. The anatomical properties of five fresh leaves and bulbs of $L$. aestivum were studied with the freehand section method. Transverse and surface sections were taken from the leaves. The upper and lower epidermis were peeled onto separate slides and mounted using glycerine for the observation of epidermal cells before being observed under a Leica DM1000 Light Microscope (Johansen, 1940; Algan, 1981).

\section{Micromorphological method}

The leaves $L$. aestivum were first examined under different magnifications $(8 \mathrm{x}-40 \mathrm{x})$ with a stereo microscope (Leica S6D, Leica Microsystems, Wetzlar, Germany), equipped with a digital camera (Leica EC3, Leica Microsystems, Wetzlar, Germany). Multiple photographs were taken using LAS EZ software. For scanning electron microscopy (SEM) studies, ten selected leaves were mounted directly on aluminum stubs with double-sided sticky tape and coated in a sputter coater with a thin layer of gold. Detailed examinations on abaxial and adaxial surfaces of the leaves were carried out under various magnifications $(300 \mathrm{x}-500 \mathrm{x})$ using scanning electron microscopy (LEO1430 VP SEM, Carl Zeiss SMT, Oberkochen, Germany) at an accelerating voltage of $20 \mathrm{kV}$. The surface observations were based on the primary ornamentation, cell boundaries, periclinal cell walls and stomata pattern (Stearn, 2004).

\section{Results}

Total soluble phenolic substances in the methanol extracts of $L$. aestivum were determined by Folin-Ciocalteu Reagent (FCR). FCR is a mixture of phosphotungustic $\left(\mathrm{H}_{3} \mathrm{PW}_{12} \mathrm{O}_{40}\right)$ and phosphomolybdic $\left(\mathrm{H}_{3} \mathrm{PMO}_{12} \mathrm{O}_{40}\right)$ acids, which are reduced to blue compounds during phenol oxidation. This color change is proportional to the amount of polyphenolic compound and is monitored on spectrophotometer at $760 \mathrm{~nm}$. The absorbance values of five different concentrations of gallic acid standard solution and FCR mixture were measured by ultraviolet spectrophotometer (Shimadzu UV-1800) at $760 \mathrm{~nm}$ wavelength. Fig. 2 shows the standard curve of gallic acid. Total phenolic content was determined at the lowest rate $(3.947 \pm 0.023 \mathrm{mg} \mathrm{GAE} / \mathrm{g}$. DW) in the bulbs of $L$. aestivum and at highest rate $(46.739 \pm 0.078 \mathrm{mg} \mathrm{GAE} / \mathrm{g}$. $\mathrm{DW}$ ) in its flowers of $L$. aestivum. In the leaves it was determined as $12.937 \pm 0.057 \mathrm{mg} \mathrm{GAE} / \mathrm{g}$. DW. The total phenolic content in the leaves, flowers and bulbs of $L$. aestivum is presented in Table 1 .

Flavonoids are generally the most important members of phenolic compounds. During the study, total flavonoid contents of extracts were calculated as catechin equivalent. The total flavonoid content was investigated by spectrophotometric method based on aluminum complex formation. Although the procedure appears to be routine, specific for luteolines and catechins, phenolic acids exhibit significant absorbance at $510 \mathrm{~nm}$ in the presence of $\mathrm{NaNO}_{2}$ in the alkaline medium. The method is based on the nitration of any aromatic ring bearing a catechol group having three or four positions which are unsubstituted or sterically blocked. After the addition of $\mathrm{Al}$ (III), a yellow complex solution formed, which immediately turned pink after the addition of $\mathrm{NaOH}$. The absorbance values of the solutions using five concentrations of catechin standard solutions were measured by ultraviolet spectrophotometer (Shımadzu UV-1800) at $510 \mathrm{~nm}$. Fig. 3 shows the standard curve of catechin. Total flavonoid content were determined as $17.350 \pm 1.970 \mathrm{mg} \mathrm{CAE} / \mathrm{g} . \mathrm{KB}$ in the flowers of $L$. aestivum, $10.620 \pm 1.670 \mathrm{mg} \mathrm{CAE} \mathrm{/} \mathrm{g.} \mathrm{KB} \mathrm{in} \mathrm{its} \mathrm{leaves,} \mathrm{and}$ $0.820 \pm 0.624 \mathrm{mg} \mathrm{CAE} / \mathrm{g} \mathrm{KB}$ in its bulbs. The total flavonoid content in the flowers, leaves and bulbs of $L$. aestivum is given in Table 2 .

DPPH is a dark crystalline powder composed of stable free radical molecules. Radical removing method was used to investigate the antioxidant capacity against free radicals methanolic extracts of $L$. aestivum flowers, leaves and bulbs. The DPPH radical is widely used in the analysis of free radical scavenging activity due to reaction formation. In this method, the proton transfer reaction between the antioxidant and DPPH free radical leads to a decrease in absorbance at $515 \mathrm{~nm}$. This process is based on monitoring by visible field spectrophotometer when the absorbance is constant. The analysis curve developed with different concentrations of the standard Ascorbic acid solution (naturally occurring organic compound with antioxidant properties) is demonstrated in Fig. 4, the inhibition curve. Percentage inhibition of total DPPH radical in $L$. aestivum flowers, leaves and bulbs is provided in Table 3 . Antioxidant activity value was given in \% inhibition and $\mathrm{mg} \mathrm{AA} / \mathrm{g}$. KB.

The DPPH test is considered to be a valid, accurate, easy and economical method for evaluating the radical scavenging activity of antioxidants (Sanchez-Moreno $e t$ al., 1998, 1998a, b). DPPH method was used to evaluate the antioxidant ability of phenolic compounds (SanchezMoreno et al., 1998). In this study, the flowers of $L$. aestivum had the highest cleaning capacity against oxidation while its bulbs had the lowest cleaning capacity against oxidation. The leaves had a slightly less oxidizing capacity than the flowers. Our findings exhibited that the flowers and leaves of $L$. aestivum were important sources of antioxidants.

L. aestivum flowers inhibited DPPH radical at the highest rate (96.24\%) however it was in its bulbs at the lowest rate (11.11\%). The DPPH scavenging activity of the flower, leave and bulb extracts were determined as $4.635 \pm$ $0.059,3.736 \pm 0.047$, and $0.590 \pm 0.123 \mathrm{mg} \mathrm{AA} / \mathrm{g} \mathrm{DW}$, respectively. 
1386

The analysis curve developed with different concentrations of standard gallic acid solutions is presented in Fig. 5. Antioxidant activities of $L$. aestivum flowers, leaves and bulbs against $\mathrm{ABTS}^{+}$radical are provided as $\mathrm{mg} \mathrm{GAE} /$ g DW in Table 4.

L. aestivum flowers inhibited $\mathrm{ABTS}^{+}$radical at the highest rate $(87.70 \%)$ whereas it was in its bulbs at the lowest rate $(30.64 \%)$. The $\mathrm{ABTS}^{+}$removal activity of flower, leaf and bulb extract samples of $L$. aestivum was determined as $7.850 \pm 0.280 \mathrm{mg}, 5.190 \pm 0.130 \mathrm{mg}$, and $2.013 \pm 0.235 \mathrm{mg} \mathrm{AA} / \mathrm{g}$. DW, respectively.

For the $\mathrm{ABTS}^{+}$radical scavenging activity, antioxidant capacity is considered to be high when inhibition values (reduction of radical levels) are $\geq 60 \%$. The method is a good indicator of the radical scavenging capacity of a given sample compared to various other methods: DPPH, FRAP, ORAC, etc. (Miliauskas et al., 2004; Djeridane et al., 2006; Katalinic et al., 2006; Rasineni et al., 2008). As in the DPPH results, the flower and leaf extracts of $L$. aestivum had more antioxidant activity than bulbs, making them important sources of antioxidant compounds.

Ascorbic acid was used as a standard solution. The increased absorbance of the reaction mixture indicated an increase in the reducing power. Fig. 6 demonstrates the standard curve of ascorbic acid. Table 5 shows tRPC in $L$. aestivum flowers, leaves and bulbs. Fig. 7 shows the comparison of the RPC between them.

The results indicated that the highest absorbance $(1,589$ \pm 0,020) was found in $L$. aestivum flowers at a concentration of $0.0175 \mathrm{mg} / \mathrm{mL}$. On the other hand, the lowest absorbance $(0.197 \pm 0.015)$ was obtained in its bulbs at a concentration of $0.0045 \mathrm{mg} / \mathrm{ml}$. Reduction activities of plant extracts are seen as an important indicator of potential antioxidant activities (Meir et al., 1995). The potassium ferricyanide reduction method is a widely used for evaluating the reduction power of plant polyphenols. In this assay, the presence of antioxidants in the test samples causes the $\mathrm{Fe}^{3+} /$ ferricyanide complex to be reduced to an $\mathrm{Fe}^{2+}$ form by giving an electron. This transformation is accompanied by Perl's Prussian blue color formation (Oyaizu, 1986).

As the concentrations of leaf and flower extracts of $L$. aestivum increased, the absorbance value increased. While the increase in absorbance value was observed at the highest rate in the flowers, the leaves was slightly lower than the flowers. The absorbance value which was already low in the bulb extracts. According to the results, the flower extracts of $L$. aestivum had the highest reducing power capacity when compared to the bulb extracts due to the increased absorbance.

The total anthocyanin content of $L$. aestivum leaves and bulb extracts was determined using spectrophotometers at two different $\mathrm{pH}\left(\mathrm{pH}_{1.0}\right.$ and $\left.\mathrm{pH}_{4.5}\right)$ and absorbance measurements were made at 510 and $700 \mathrm{~nm}$ wavelengths for each extract. Table 6 shows the total anthocyanin content in $L$. aestivum fractions. The total anthocyanin content was calculated using the following formula using cyanidine-3-glycoside equivalent:

$\mathrm{A}=\left[\left(\mathrm{A}_{510}-\mathrm{A}_{700}\right) \mathrm{pH}_{1.0}-\left(\mathrm{A}_{510}-\mathrm{A}_{700}\right) \mathrm{pH}_{4.5}\right]$.

The highest anthocyanin content of $L$. aestivum was found to be $0.018 \pm 0.0003 \mu \mathrm{g}$ cg-3-glkt/g. DW in its bulbs.
The anthocyanin content was determined as $0.003 \pm 0.001$ $\mu \mathrm{g} \mathrm{cg-3-glkt/g.} \mathrm{DW} \mathrm{in} \mathrm{the} \mathrm{leaves} \mathrm{and} 0.008 \pm 0.001 \mu \mathrm{g} c g-3-$ glkt/g. DW in the leaves.

Methanolic extract was used to determine polyphenolic compounds in the extracts. Gallic acid, genticic acid, vanillic acid, caffeic acid, syringic acid, sinapinic acid, p-coumaric acid, ferrulic acid, rosmarinic acid, protocatechic acid, catechin, naringenin and quercetin are used as standards. Polyphenolic compounds in L. aestivum fractions and their amounts are given in Table 7 and Fig. 8. In the flowers and leaves, the most compound was naringenin. The most genticic acid was found in the bulbs.

The antimicrobial activities of $L$. aestivum flowers, leaves and bulbs were investigated against five pathogenic bacterial strains (gram positive: Bacillus subtilis and Staphylococcus aureus; gram negative: Pseudomonas aerouginosa, Escherichia coli and Klebsiella pneumoniae). The results of antibacterial activities were given in Table 8 . The results showed that the extracts had no activity against these strains. According to previous studies, DMSO (dimethyl sulfoxide) has no significant effect on the biological environment. The results show that $L$. aestivum flower, leaf and bulb extracts had no activity on the selected bacterial strains.

In addition to antibacterial activities, extracts were exposed to antifungal activities against eight fungal strains (1. Mucor plumbeus, 2. Trichoderma longibrachiatum, 3. Fusarium solani, 4. Penicillium glabrum, 5. Alternaria citri, 6. Cladosporium cladosporioides, 7. Trichoderma atroviride, 8. Penicillium janthinellum) and zone diameters of inhibition $(\mathrm{mm})$ are given in Table 9. Fig. 9 shows the antifungal activity of the control (DMSO). Fig. 10 shows the antifungal activity of $L$. aestivum leaf extract. DMSO (dimethyl sulfoxide) was used as a control in this test. The antifungal activity of $L$. aestivum leaf extract was tested against eight fungi and displayed the most effect against Alternaria citri. Furthermore, it had little effect against Fusarium solani, Penicillium glabrum and Cladosporium cladosporioides. L. aestivum bulbs extract showed an effect against Penicillium glabrum and Alternaria citri. There is no effect on other fungi.

The leaf cross-sections showed that the epidermis was composed of monolayered isodiametric and elongated cells on both adaxial and abaxial surfaces. The upper and lower epidermal cells were nearly equal in size and covered with thin cuticles, approximately 1.3-2.2 $\mu \mathrm{m}$ in thickness. The leaf was amphystomatic and isobilateral and its midvein was unraised. The mesophyll tissue was composed of many amounts of chloroplasts and isodiametric (polygonal) or irregular parenchyma cells with large intercellular spaces. The mesophyll also consisted of large lysigenous cavities and contained vascular tissue arranged in collateral vascular bundles that were similar in appearance and size to the main vascular bundles. These cavities were distinguished by vascular bundles. Needle-shaped raphide crystals of calcium oxalate were obviously observed in the mesophyll. The vascular bundles were surrounded by several layers parenchymatous bundle sheat cells. Bundle sheath extensions projected as ribs on both sides. The leaf surface section displayed that the structure of stomata on both leaf surcafes was tetracytic and arranged in parallel rows to the 
axis of the leaf. The number of the stomata was 4 and 5 per leaf at 20x. In cross section of the bulb, the outer region, epidermis, comprised one layer of rectangular cells covered with cuticule. Beneath the epidermis, large amounts of compound starch grains were observed in large and rectangular or almost square parenchyma cells (Fig. 11).

Trichomes were not observed in the leaf surface. Leaf epidermal cells had conspicuous boundaries and their membranes on periclinal walls were striate. The epidermal cells had slightly undulate anticlinal walls but anticlinal walls of some epidermal cells were almost straight. Stomata were present on the abaxial and adaxial surfaces. They were mainly opened and slightly raised above the both surfaces of the leaf (Fig. 12).

Table 1. Total phenolic content of flowers, leaves and bulbs of L. aestivum (mg. gallic acid / g. DW.)

\begin{tabular}{cc}
\hline Parts of $L$. aestivum & Total phenolic content $(\mathrm{mg} \mathrm{GAE} / \mathrm{g}$. DW) \\
\hline Flower & $46.739 \pm 0.078$ \\
Leaf & $12.937 \pm 0.057$ \\
Bulb & $3.947 \pm 0.023$ \\
\hline
\end{tabular}

Each value is expressed as mean \pm standard deviation $(\mathrm{n}=3)$.

Table 2. Total flavonoid content of flowers, leaves and bulbs of L. aestivum (mg catechin / g. DW)

\begin{tabular}{cc}
\hline Parts of L. aestivum & Total flavonoid content (mg. CAE / g. KB) \\
\hline Flower & $17.350 \pm 1.970$ \\
Leaf & $10.620 \pm 1.670$ \\
Bulb & $0.820 \pm 0.624$ \\
\hline
\end{tabular}

Each value is expressed as mean \pm standard deviation $(\mathrm{n}=3)$.

Table 3. Free radical scavenging activity (DPPH) of the flowers, leaves and bulbs of $L$. aestivum as inhibition values \% (antioxidant activity value of each sample as mg ascorbic acid / $\mathrm{g} \mathrm{KB})$ )

\begin{tabular}{ccc}
\hline Parts of $L$. aestivum & Inhibition $(\%)$ & Antioxidant activity $(\mathrm{mg}$ AAE / g. DW) \\
\hline Flower & 96.24 & $4.635 \pm 0.059$ \\
Leaf & 89.70 & $3.736 \pm 0.047$ \\
Bulb & 11.11 & $0.590 \pm 0.123$ \\
\hline
\end{tabular}

Each value is expressed as mean \pm standard deviation $(\mathrm{n}=3)$.

Table 4. Antioxidant activity of flowers, leaves and bulbs of $L$. aestivum against $\mathrm{ABTS}^{+}$radical (mg gallic acid / g. DW.)

\begin{tabular}{ccc}
\hline Parts of $L$. aestivum & Inhibition $(\%)$ & Antioxidant activity $(\mathrm{mg} \mathrm{GAE} / \mathrm{g} . \mathrm{KB})$ \\
\hline Flower & 87.70 & $7.850 \pm 0.280$ \\
Leaf & 70.90 & $5.190 \pm 0.130$ \\
Bulb & 30.64 & $2.013 \pm 0.235$ \\
\hline
\end{tabular}

Each value is expressed as mean \pm standard deviation $(\mathrm{n}=3)$.

Table 5. Reducing capacity of flowers, leaves and bulbs of L. aestivum $(\mathrm{mg} / \mathrm{mL})$

\begin{tabular}{ccccc}
\hline Parts of $L$. aestivum & 0,0045 & 0,0089 & 0,0132 & 0,0175 \\
$(\mathrm{mg} / \mathrm{mL})$ & $(\mathrm{mg} / \mathrm{mL})$ & $(\mathrm{m} / \mathrm{mL})$ & $1,25 \pm 0,077$ & $1,589 \pm 0,020$ \\
\hline Flower & $0,745 \pm 0,065$ & $0,905 \pm 0,055$ & $1,133 \pm 0,043$ & $1,359 \pm 0,010$ \\
Leaf & $0,530 \pm 0,050$ & $0,790 \pm 0,035$ & $0,247 \pm 0,005$ & $0,262 \pm 0,037$ \\
\hline Bulb & $0,179 \pm 0,015$ & $0,233 \pm 0,067$ & &
\end{tabular}

Each value is expressed as mean \pm standard deviation $(n=3)$.

Table 6. Total anthocyanin content of flowers, leaves and bulbs of L. aestivum ( $\mu \mathrm{g} \mathrm{cg}-3$-glkt/g. DW)

\begin{tabular}{cc}
\hline L. aestivum fractions & Total anthocyanin $(\mu \mathrm{g} \mathrm{cg}$-3-glkt $/ \mathrm{g}$. KB) \\
\hline Flower & $0,003 \pm 0,001$ \\
Leaf & $0,008 \pm 0,001$ \\
Bulb & $0,018 \pm 0,003$ \\
\hline
\end{tabular}

Each value is expressed as mean \pm standard deviation $(\mathrm{n}=3)$.

Table 7. L. aestivum polyphenolic compounds and their amounts

\begin{tabular}{cccc}
\hline Polyphenolic compounds & $\begin{array}{c}\text { Flower } \\
(\mathrm{mg} / 100 \mathrm{~g} . \mathrm{DW})\end{array}$ & $\begin{array}{c}\text { Leaf } \\
(\mathrm{mg} . / 100 \mathrm{~g} . \mathrm{DW})\end{array}$ & $\begin{array}{c}\text { Bulb } \\
(\mathrm{mg} . / 100 \mathrm{~g} . \mathrm{DW})\end{array}$ \\
\hline Gallic acid & 45 & 39 & - \\
Protocatechic acid & 5 & 2 & - \\
Syringic acid & 51 & 42 & - \\
Caffeic acid & - & 3 & 9 \\
p-coumaric acid & 93 & 84 & - \\
Naringenin & 131 & 126 & - \\
Rosmarinic acid & 123 & 110 & - \\
Genticic acid & - & - & 110 \\
\hline
\end{tabular}


1388

Table 8. Antimicrobial analysis of $L$. aestivum flower, leaf and bulb extracts

\begin{tabular}{cccccc}
\hline L. aestivum & \multicolumn{3}{c}{ Gram positive bacteria } & \multicolumn{2}{c}{ Gram negative bacteria } \\
\cline { 2 - 6 } fractions & Bacillus subtilis & Staphylococcus aureus & Psendomonas aeruginosa & Escherichia coli & Klebsiella pneumoniae \\
\hline Flower & - & - & - & - & - \\
Leaf & - & - & - & - & - \\
Bulb & - & - & - & - & - \\
\hline
\end{tabular}

Table 9 . Antifungal activity analysis of $L$. aestivum extracts

\begin{tabular}{|c|c|c|c|c|}
\hline \multirow[b]{2}{*}{ Mushroom strain } & \multicolumn{3}{|c|}{ Zones of $L$. aestivum extracts } & \multirow{2}{*}{$\begin{array}{c}\text { DMSO (Control) } \\
(\mathrm{mm})\end{array}$} \\
\hline & $\begin{array}{c}\text { Flower } \\
(\mathrm{mm})\end{array}$ & $\begin{array}{c}\text { Leaf } \\
(\mathrm{mm})\end{array}$ & $\begin{array}{l}\text { Bulb } \\
(\mathrm{mm})\end{array}$ & \\
\hline Mucor plumbeus & - & - & - & - \\
\hline Trichoderma longibrachiatum & - & - & - & - \\
\hline Fusarium solani & 14 & 11 & 8 & 10 \\
\hline Penicillium glabrum & 25 & 21 & 23 & 20 \\
\hline Alternaria citri & 20 & 17 & 16 & 12 \\
\hline Cladosporium cladosporioides & 32 & 28 & 23 & 27 \\
\hline Trichoderma atroviride & - & - & - & - \\
\hline Penicillium janthinellum & 24 & 18 & 16 & 18 \\
\hline
\end{tabular}

Table 10. Analytical conditions of HPLC for the analysis of polyphenolic compounds

\begin{tabular}{cc}
\hline Parameter & Conditions \\
\hline Column & Ace Brand C18 $(4.6 \mathrm{~mm} \times 150 \mathrm{~mm}, 5 \mu \mathrm{m})$ \\
Flow rate & $0.5 \mathrm{~mL} / \mathrm{min}$ \\
Injection volume & $10 \mu \mathrm{L}$ \\
Detection & $254,275,305$ and $320 \mathrm{~nm}$ \\
Run time & $40 \mathrm{~min}$ \\
\hline
\end{tabular}

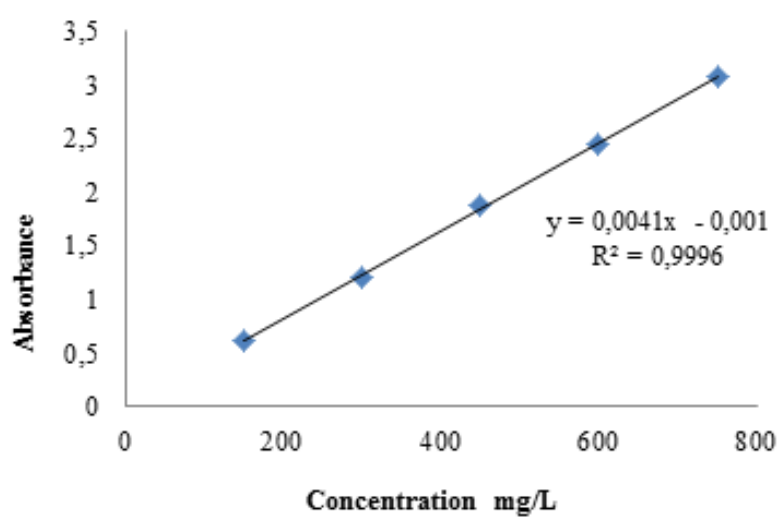

Fig. 2. Gallic acid standard curve

Inhibition Curve of Ascorbic Acid

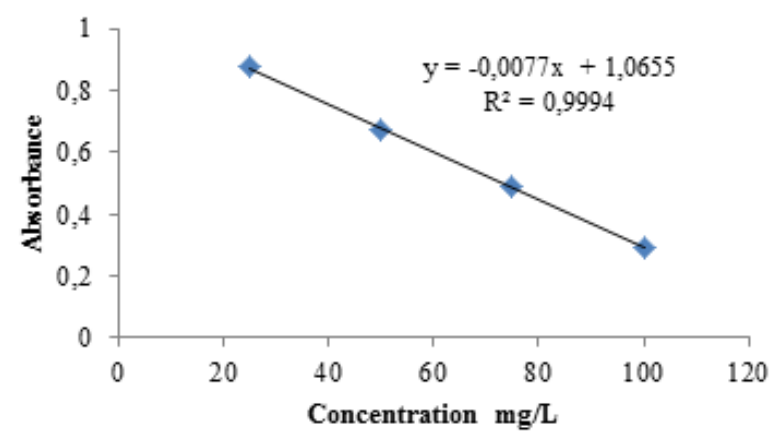

Fig. 4. Inhibition curve of ascorbic acid

\section{Catechin Standard Curve}

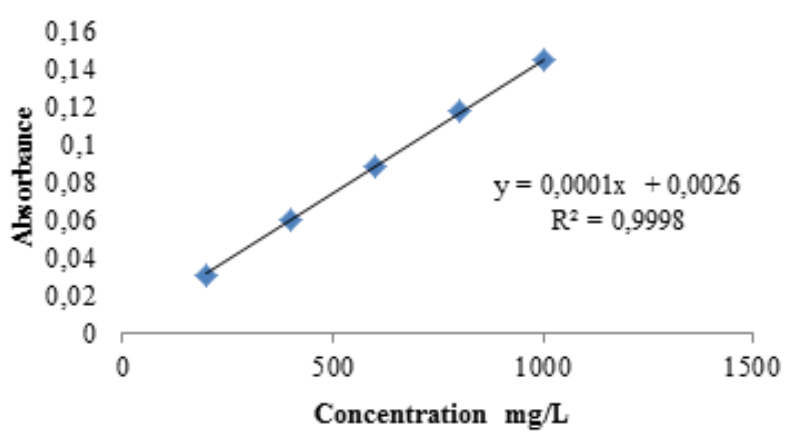

Fig. 3. Catechin standard curve

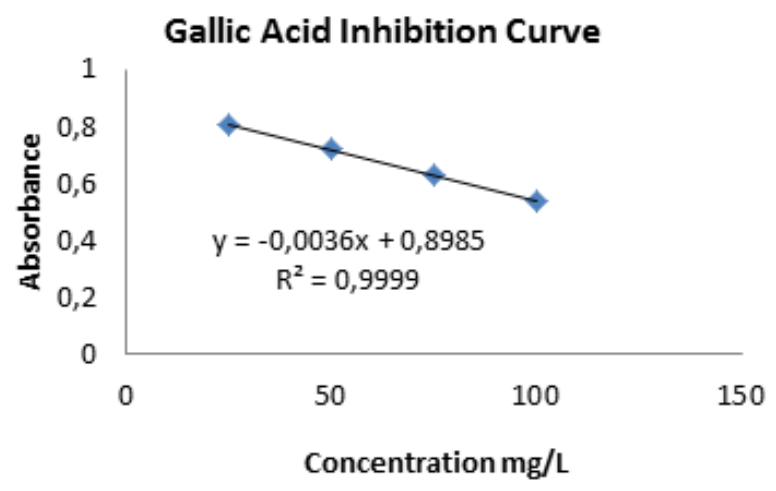

Fig. 5. Gallic acid inhibition curve 


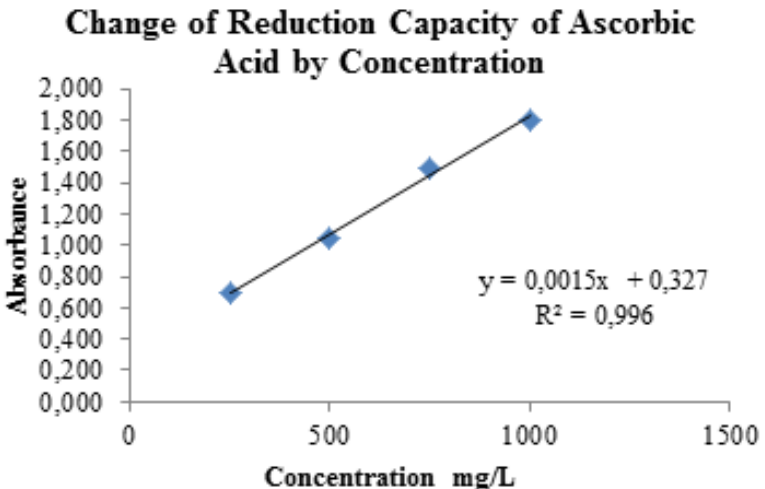

Fig. 6. Standard curve of ascorbic acid

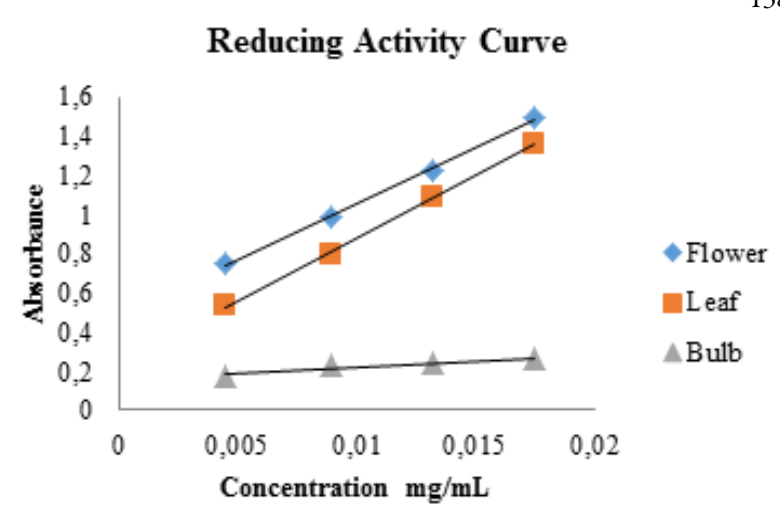

Fig. 7. Comparison of reductive capacity of flowers, leaves and bulbs

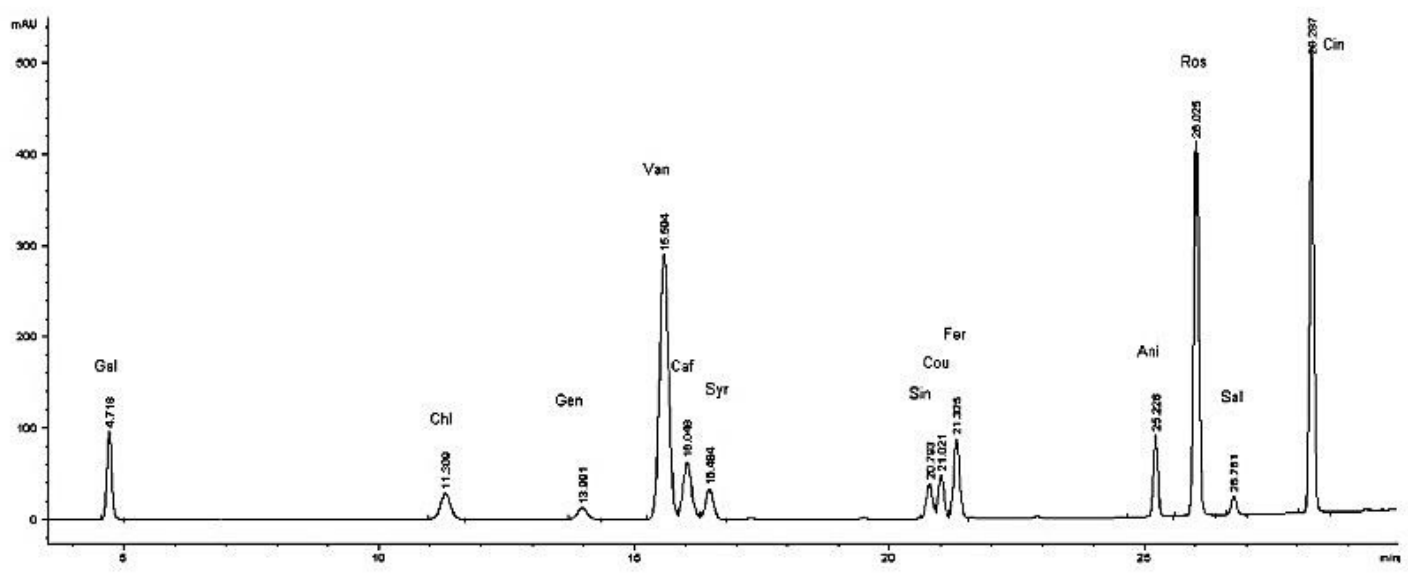

Fig. 8. Chromatogram of polyphenolic compounds standards

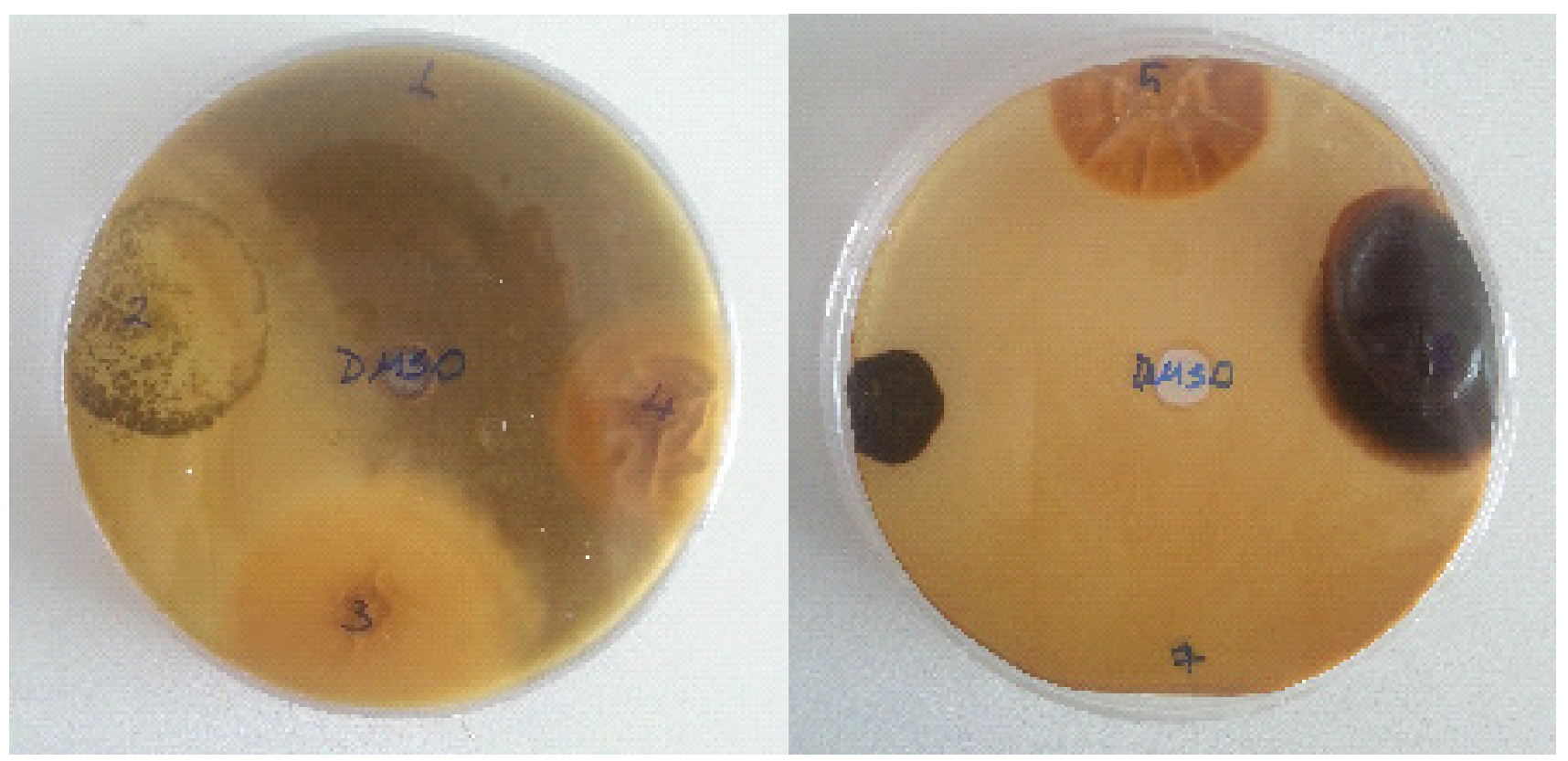

Fig. 9. Antifungal activity of control (DMSO) 
1390

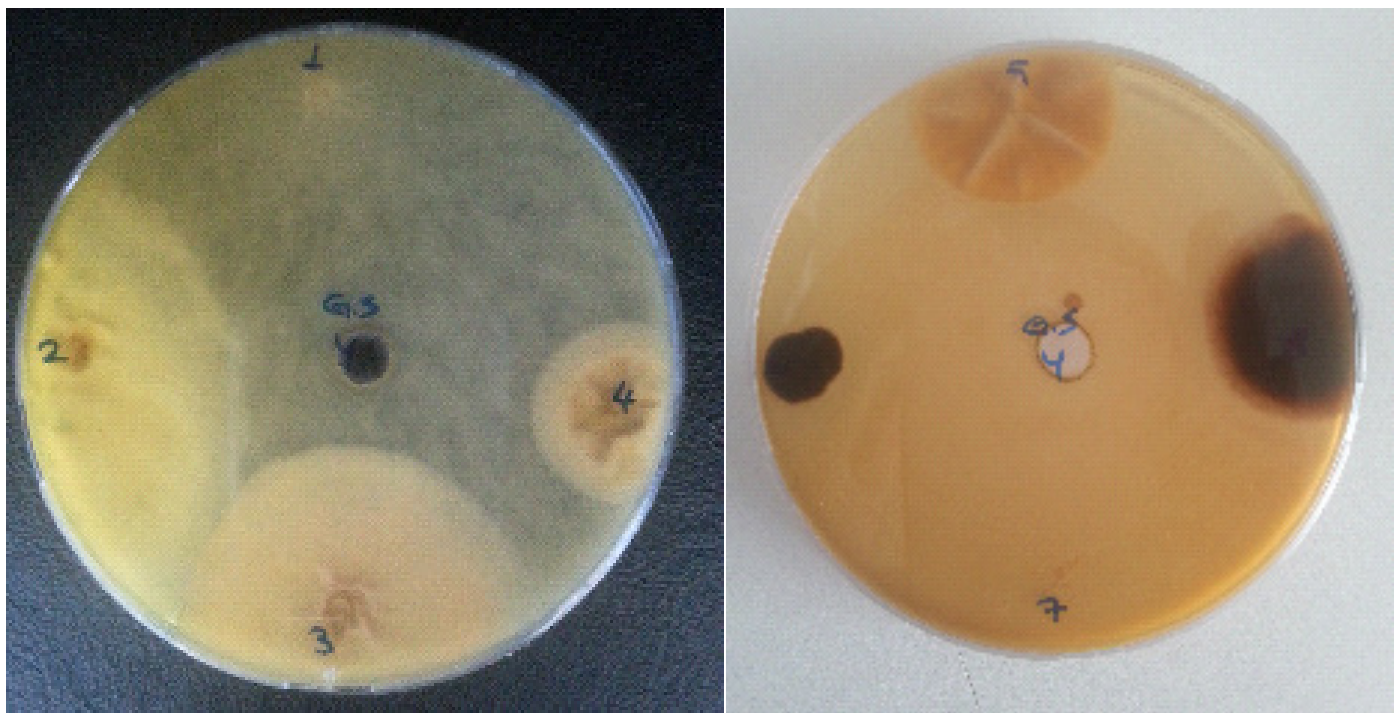

Fig. 10. Antifungal activity of leaf extract of $L$. aestivum
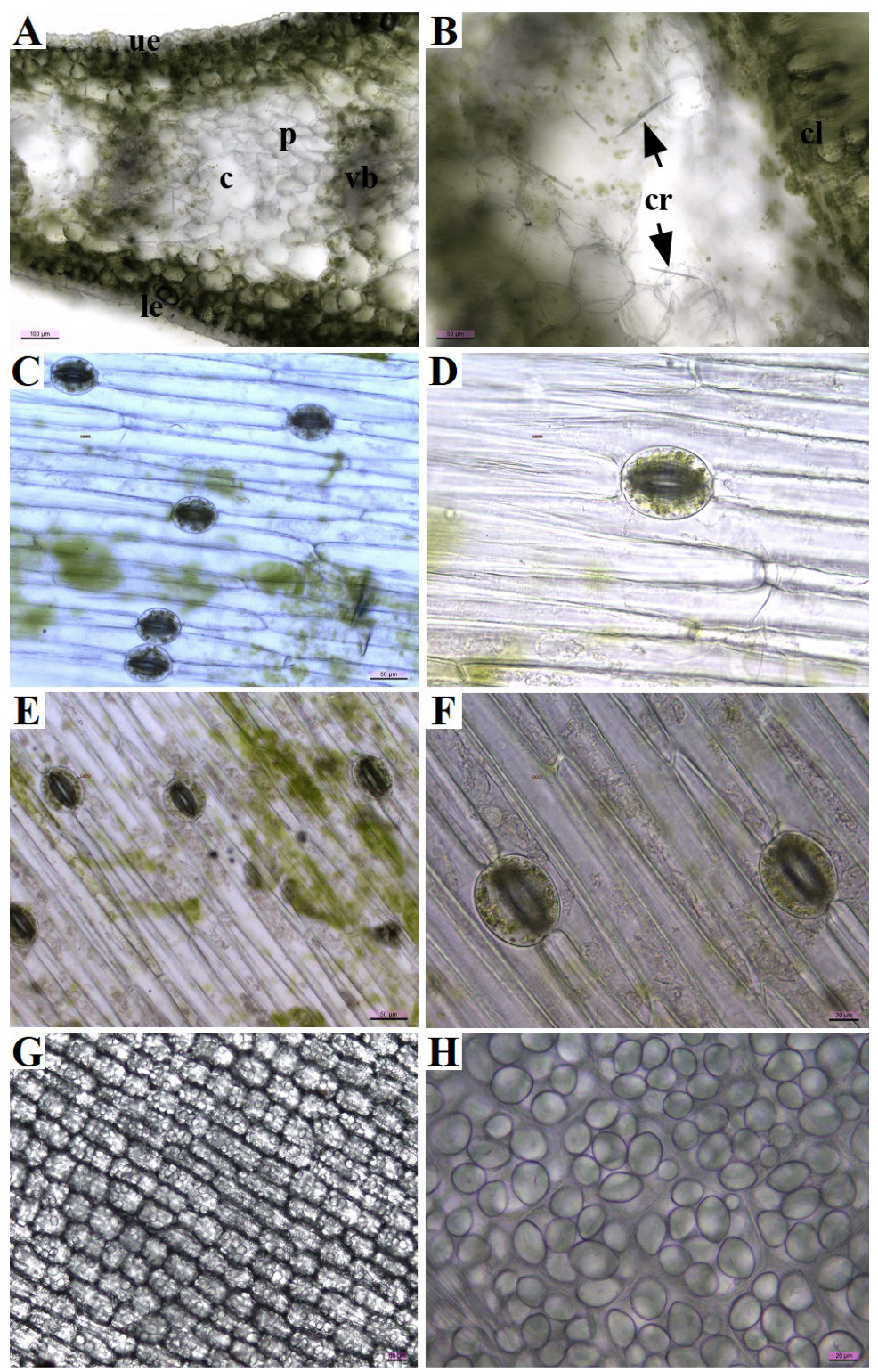

Fig. 11. Light microscope micrographs of leaf cross-section and surface sections of L. aestivum (E-F) and its bulb cross-section (GH). A. General shape of the leaf. c: lysigenous cavity, le: lower epidermis, , p: parenchyma cells, ue: upper epidermis, vb: vascular bundle. B. The mesophyll tissue. cr: raphide crystals (arrows), cl: chloroplasts. C-D: The adaxial surface of the leaf with stomata. E-F: The abaxial surface of the leaf with stomata. G-H: Parenchyma cells with many compound starch grains 


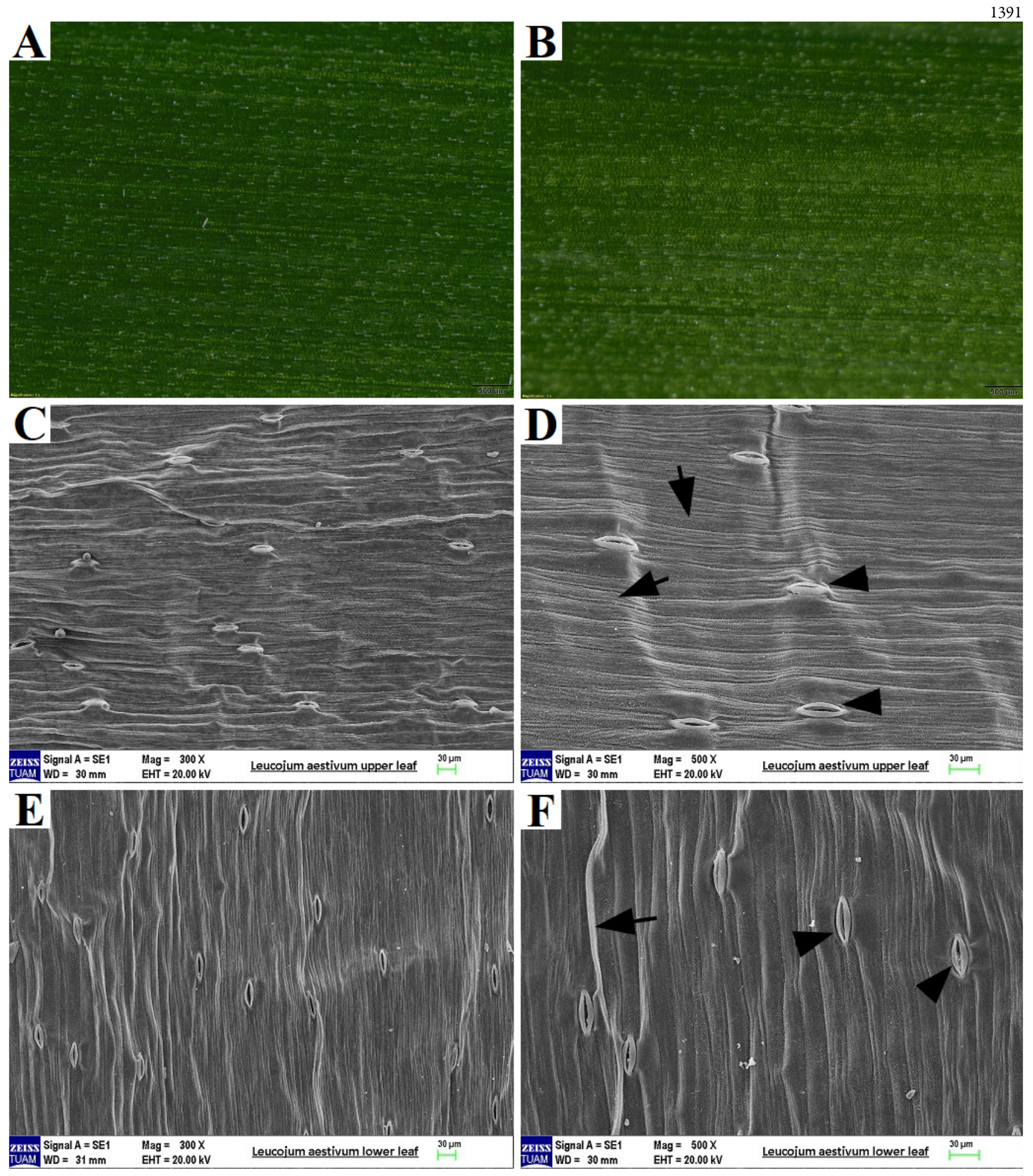

Fig. 12. Stereomicroscope (A-B) and SEM (C-F) micrographs of L. aestivum leaf. A, C-D. Adaxial epidermis. B, E-F. Abaxial epidermis. Striations showed by arrows and stomata showed by arrowheads 
1392

\section{Discussion}

To date, studies on $L$. aestivum have been directed towards the determination of alkaloid content, especially galantamine. The antioxidant activity, polyphenolic content, antibacterial activity of the species has not been studied yet. The recent researh showed that $L$. aestivum (especially its leaves and flowers) exhibited antioxidant activity and contained significant amounts of polyphenols. Today, the search for natural antioxidants to replace synthetic antioxidants for the future continues rapidly. It is considered that plant extracts with high antioxidant activity are determined by this type of studies, their antioxidant effects in food systems are investigated and the continuity of the studies towards industrial application is considered.

The antimicrobial activity of methanol extracts of $L$. aestivum flowers, leaves and bulbs was investigated against five pathogenic bacterial strains. The results showed that these extracts had no activity against these strains. The antifungal activity of methanol extracts of its flowers, leaves and bulbs against eight fungal strains was studied. The findings indicated that the flowers and leaves had the most effective antifungal effect against Alternaria citri. Moreover, little antifungal effect has been determined against Fusarium solani, Penicillium glabrum and Cladosporium cladosporioides.

This study presents significant findings on the anatomy and micromorphology of $L$. aestivum. Metcalfe (1960) offered the general anatomical characteristics of the family Amaryllidaceae. Our findings on the leaf components are mostly consistent with earlier studies (Ščepánková and Hudák, 2004). In this study, we report for the first time presence of raphide crystals of calcium oxalate in the mesophyll of the leaf. In most species, stomata are present on both leaf surfaces, while in others they are restricted to the abaxial or the adaxial surface (Rudall, 2007). Our observations showed that they are present on both surfaces of $L$. aestivum leaves. In the monocotyledones, they are parallel to the axis of the leaf (Dahlgren et al., 1985). We observed that the stomatal axes were oriented parallel to the long axis of the leaf. As in the result of the previous study (Ščepánková and Hudák, 2004), we recognized that the mesophyll was interrupted by large cavities separated by vascular bundles.

\section{Conclusions}

The current study comprehensively presents findings on polyphenolics, antioxidant and antimicrobial activity, anatomy and micromorphology of different organs of Leucojum aestivum (i.e., flowers, leaves and bulbs). The flower and leaf extracts were determined to have more antioxidant activity than the bulbs. The results indicated that the species included important amounts of polyphenols. In the leaves of Leucojum aestivum, raphide crystals were first found. In the bulbs, many starch grains were detected. The micromorphology of the leaf showed that its epidermal cells had prominent boundaries and striate periclinal walls.

\section{Acknowledgements}

This study is a part of the M.Sc. dissertation of the first author at Department of Molecular Biology and Genetics at the Institute of Natural and Applied Sciences, Usak University, Usak, Turkey. We thank Prof. Dr. Safiye Elif Korcan at Usak University for her help in antimicrobial and antifungal studies.

\section{Conflict of Interest}

The authors declare that there are no conflicts of interest related to this article.

\section{References}

Algan G (1981). Bitkisel dokular için mikroteknik. Frrat Üniversitesi Fen Edebiyat Fakültesi Yaynlan, İstanbul.

Atay S (1996). Soğanlı bitkiler: Türkiye'den ihracatı yaplan türlerin tanıtım ve üretim rehberi. Doğal Hayatı Koruma Derneği, İstanbul, Turkey.

Benedec D, Oniga I, Muresan B, Mot AC, Damian G, Nistor A,... Vlase L (2014). Contrast between water and ethanol based antioxidant assays: aspen (Populus tremula) and black poplar (Populus nigra) extracts as a case study.Journal of Food Quality 37:259-267.

Benedec D, Hanganu D, Oniga I, Tiperciuc B, Olah N, Raita O, ... Vlase L (2015). Assessment of rosmarinic acid content in six Lamiaceae species extracts and their antioxidant and antimicrobial potential. Pakistan Journal of Pharmaceutical Sciences 28(6):2297-303.

Benedec D, Hanganu D, Oniga I, Filip L, Bischin C, Silaghi-Dumitrescu R, ... Vlase L (2016). Achillea schurii flowers: chemical, antioxidant, and antimicrobial investigations. Molecules 21(8):1050.

Berber İ (2013). Sinop'da yetişen bazı bitkilerin metanolik ekstraktlarnnın antibakteriyal ve antifungal aktivitelerinin belirlenmesi. Karaelmas Science and EngineeringJournal 3(1):10-16.

Chang CC, Yang MH, Wen MH, Cern JC (2002). Estimation of total flavonoid content in propolis by two complementary colorimetric methods.Journal of Food and Drug Analysis 10(3):178-182.

Cherkasov OA, Tolkachev ON (2002). Naricisus and other Amaryllidaceae as sources of galanthamine. In: Hanks GR (Ed). The genus Narcisus. NY:Taylor \& Francis, New York, USA pp 242-256.

Dahlgren RMT, Clifford HT, Yeo PF (1985). The families of the monocotyledons: structure, evolution, and taxonomy. Springer, Heidelberg, Berlin.

De Groot R, Wilson AM, Boumans JMR (2002). A typology for the classification and valuation of ecosystem functions, goods and services. Ecological Economics 41(3):393-408.

Demir A (2014). Medical resource value appraisal for $L$. aestivum in Turkey. American Journal of Alzheimer's Disease and Other Dementias 29(5):448-451.

Diop MF, Hehn A, Ptak A (2007). Hairy root and tissue cultures of Leucojum aestivum L. - relationships to galanthamine content. Phytochemistry Reviews 6(1):137-141.

Djeridane A, Yousfi M, Nadjemi B, Bouttasouna D, Stocker P, Vidal N (2006). Antioxidant activity of some Algerian medicinal plants extracts containing phenolic compounds. Food Chemistry 97:654660. 
Elzaawely AA, Tawata S (2012). Antioxidant activity of phenolic rich fraction obtained from Convolvulus aruensis L. leaves grown in Egypt. Asian Journal of CropScience 4(1):32-40.

Ghaedi M, Nejad MY,DelshadL (2015). Synergistic effects of Taxus baccata extract mixtures with silver nanoparticles against bacteria and fungal. International Journal of Bio-Inorganic Hybrid Nanomaterials 4(1):2530.

Giusti MM, Rodriguez-Saona LE, Wrolstad RE (1999). Molar absorptivity and color characteristics of acylated and non-acylated pelargonidin-based anthocyanins. Journal of Agricultural and Food Chemistry 47(11):4631-4637.

Jayanthi P, Lalitha P (2011). Reducing power of the solvent extracts of Eichhornia crassipes (Mart.) Solms. International Journal of Pharmacy and Pharmaceutical Sciences 3(3):126-128.

Johansen DA (1940). Plant microtechnique.New York, McGraw-Hill.

Katalinic V, Milos M, Kulisic T, Jukic M (2006). Screening of 70 medicinal plant extracts for antioxidant capacity and total phenols. Food Chemistry 94:550-557.

Klosi R, Mersinllari M, Gavani E (2016). Galantamine content in Leucojum aestivum populations grown in northwest Albania. Albanian Journal of Pharmaceutical Sciences. 3(1):1-3.

Meir S, Kanner J, Akiri B, Hadas SP (1995). Determination and involvement of aqueous reducing compounds in oxidative defence systems of various senescing leaves. Journal of Agricultural and Food Chemistry 43:1813-1819.

Metcalfe CR (1960). Anatomy of the monocotyledons. Clarendon Press, Oxford.

Miliauskas G, Venskutonis PR, van Beek TA (2004). Screening of radical scavenging activity of some medicinal and aromatic plant extracts. Food Chemistry 85:231-237.

Oyaizu M (1986). Studies on products of browning reaction-antioxidative activities of products of browning reaction prepared from glucosamine. The Japanese Journal of Nutrition and Dietetics 44:307-315.

Rasineni GH, Siddavattam D, Reddy AR (2008). Free radical quenching activity and polyphenols in three species of Coleus. Journal of Medicinal Plants Research 2:285-291.
Rudall PJ (2007). Anatomy of flowering plants an introduction to structure and development. Cambridge University Press, New York.

Sanchez-Moreno C, Larrauri JA, Saura-Calixto F (1998). A procedure to measure the antiradical efficiency of polyphenols. Journal of the Science ofFood and Agriculture 79:270-276.

Sanchez-Moreno C, Larrauri JA, Saura-Calixto F (1999a). Free radical scavenging capacity and inhibition of wines, grape juices and related polyphenolic constituents. Food Research International 32:407-412.

Sanchez-Moreno C, Larrauri JA, Saura-Calixto F (1999b). Free radical scavenging capacity of selected red, rose and white wines. Journal of the Science of Food and Agriculture 79:1301-1304.

Simpson DR, Sedjo AR, Reid WJ (1996). Valuing biodiversity for use in pharmaceutical research.Journal of Political Economy 104(1):163-185.

Stearn WT (2004). Botanical latin ( $4^{\text {th }} \mathrm{ed}$ ). Timber Press, Portland, Oregon.

Ščepánková I,HudákJ (2004). Leaf and tepal anatomy, plastid ultrastructure and chlorophyll content in Galantusnivalis L. and Leucojum aestivum L. Plant Systematics and Evolution 243:211-219.

Thaipong K, Boonprakob U, Crosby K, Cisneros-Zevallos L, Byrne DH (2006). Comparison of ABTS, DPPH, FRAP, and ORAC assays for estimating antioxidant activity from guava fruit extracts. Journal of Food Composition and Analysis 19(6-7):669-675.

Villano D, Fernandez-Pachon MS, Moya ML, Troncoso AM, GarciaParrilla MC (2007). Radical scavenging ability of polyphenolic compounds towards DPPH free radical. Talanta 71(1):230-235.

Vlase L, Benedec D, Hanganu D, Damian G, Csillag I, Sevastre B, ... Tilea I (2014). Evaluation of antioxidant and antimicrobial activities and phenolic profile for Hyssopus officinalis, Ocimum basilicum and Teucrium chamaedrys. Molecules 19(5):5490-507.

Wen D, Li CH, Di H, Liao Y, Liu H (2005). A universal HPLC method for the determination of phenolic acids in compound herbal medicines. Journal of Agricultural and Food Chemistry 53:66246629. 